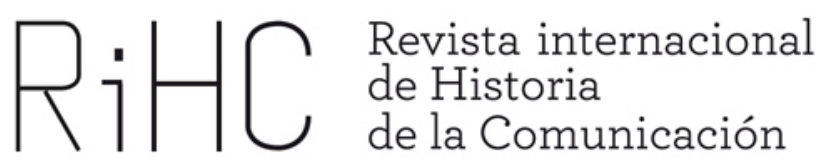

\title{
PROPAGAR LA LIBERTAD (1808-1814)
}

DOI: http://dx.doi.org/10.12795/RiHC.2013.i01.03

Antonio Laguna Platero

Universidad de Castilla-La Mancha

antonio.laguna@uclm.es

Resumen: La propaganda deviene un factor clave en el primer intento de transformación jurídica que se produce a partir de 1808. Sin embargo, lo que se propone es reconstruir el proceso de comunicación no sólo desde la perspectiva de los medios y soportes empleados, (tendencia dominante hasta la fecha) sino de los directores y receptores de los mensajes.

Palabras clave: Propaganda, prensa, opinión pública

Abstract: Propaganda becomes a key factor in the first attempt at legal transformation that occurs from 1808. However, it is proposed to reconstruct the process of communication not only from the perspective of media and supports used (mainstream to date) but the directors and receivers of messages.

Keywords: Propaganda, press, public opinion. 
“¿Cómo explicar el curioso fenómeno de que la Constitución de 1812, anatemizada después por las testas coronadas de Europa reunidas en Verona como la más incendiaria invención del jacobinismo, brotara de la cabeza de la vieja España monástica y absolutista precisamente en la época en la que ésta parecía consagrada por entero a sostener la guerra santa contra la revolución?" Karl Marx, "Revolución en España", New York Tribune, 24.11.1854

"Pero, hombre, explícate mejor: di a Su Majestad en qué te fundas para creer que esa Constitución que ahora defiendes es mejor que otra cualquiera'. Tanto le apremiaron, que el pobre chico se arrancó con sus razones. 'Pues yo no sé... lo que sé es que el año 20, en mi pueblo, que es la Coruña, para servirles, estaba libre la sal (Risas) y libre el tabaco". Pérez Galdós: Episodios Nacionales, "Luchana".

\section{La propaganda, condición de la revolución}

Mayo de 1808, comienza el siglo de la revolución. Como consecuencia del vacío de poder que genera la invasión francesa, se inicia en España el primer acto del proceso revolucionario que pondrá fin al milenario régimen feudal que dominaba las tierras de la península ${ }^{1}$. Fue un inicio intenso aunque poco extenso en la cronología, apenas seis años, y sus efectos de cambio se harían notar en todos los órdenes. En pocas palabras, a partir de entonces la vida de los españoles de ambos hemisferios ya no volvería ser igual, a pesar de la reacción de 1814.

De todas las novedades que se produjeron en aquel sexenio, una destaca de forma muy especial ya que será clave para entender los acontecimientos que se sucedieron a lo largo del siglo mientras duró dicho proceso revolucionario. Nos referimos a la enorme necesidad de comunicación que se generó para hacer triunfar, o fracasar, la revolución. Por de pronto, se multiplicó la necesidad de información oficial como consecuencia de la convocatoria, por primera vez en la historia y mediante un sistema de juntas provinciales, de unas elecciones por sufragio universal indirecto para elegir diputados a un parlamento constituyente. Ordenes, circulares, disposiciones, oficios y

\footnotetext{
1 “La revolución burguesa, 1834-43, constituye el núcleo de un período cronológicamente más dilatado, el proceso revolucionario burgués, 1808-74, que comprende, además de la revolución, cuatro situaciones revolucionarias burguesas, las antifeudales de 1808-14 y 1820-23 y las democráticoburguesas de 1854-56 y 1868-74", SEBASTIÀ, E.: "Estudio Preliminar" a la obra de José Antonio Piqueras, El taller y la escuela en la Valencia del siglo XIX. Ayuntamiento de Valencia, 1983, p. 15. Cf. SEBASTIÀ DOMINGO, E. y PIQUERAS ARENAS, J.A (1987): Pervivencias feudales y revolución democrática. Edicions Alfons el Magnànim. València: IVEI.
} 
otras vías de comunicación oficial se intensificaron ante los retos de ganar una guerra y hacer una revolución jurídica. A continuación, la libertad de imprenta, marco jurídico que engloba el derecho fundamental de expresión, se hizo realidad por primera vez en el comienzo del proceso constituyente, convirtiendo el debate de ideas, la publicidad de los actos y la participación social en nuevos parámetros de la acción política de buena parte de aquel sexenio. Por extensión, el ámbito de lo público experimenta la primera gran novedad: se llena de discursos y de periódicos, hasta tal extremo que un periódico gaditano salió a la calle en 1811 con el escatológico nombre de Diarrea de las Imprentas. ${ }^{2} \mathrm{Y}$, por supuesto, se generó una gran necesidad de persuadir a importantes sectores de la población para que se sumaran a favor o en contra del gran símbolo del cambio, la Constitución de 1812 y la nueva sociedad que alumbraba. En definitiva, la revolución es inseparable de la comunicación de ideas a la población que tiene que actuar de fuerza motriz del cambio, por el procedimiento y soporte que fuere.

De igual forma, la contrarrevolución, integrada por la suma de todos los agraviados por las normas gaditanas, utilizará la propaganda de forma intensa para lograr sus objetivos. Y en este papel, la Iglesia será con distancia el principal agente comunicador. Gracias a su amplia implantación territorial, a la disciplina vertical con la que organiza sus mensajes - de obispo provincial a párroco local- $y$, sobre todo, a su alta credibilidad entre los temerosos del más allá, la Iglesia será un factor reaccionario fundamental contra las ideas y principios expuestos en Cádiz. A ellos les cabe el columbrar el origen del pensamiento reaccionario español que, basado en la trilogía Dios-Patria-Rey, tanto fructificará hasta bien entrado el siglo XX.

La revolución, por tanto, no consiste sólo en la transmisión de ideas de líderes y pensadores. Es, sobre todo, propaganda adaptada a la población a la que se dirige para ganar las conciencias que nutre el movimiento revolucionario. Nos interesa este último punto de vista. Sobre todo porque hasta la fecha nuestra preocupación central a la hora de explicar las propagandas revolucionarias ha consistido en reconstruir medios y mensajes, incluso en sus múltiples y singulares formas, pero muy poco en estudiar a los receptores o a los directores de la propaganda. Y si algo destaca en el cambio que se opera a partir de 1808 es la de la igualdad jurídica para todas las personas, acreditada con el título de ciudadano perteneciente a una nación. La idea revolucionaria de la igualdad nos permite entender el nacimiento del público como destinatario de un proceso comunicativo que tiene a la prensa recién nacida como principal medio emisor; nos permite entender la irrupción de la opinión pública como nueva fuerza en la vida política del país; y nos permite, en suma, valorar por qué la

\footnotetext{
${ }^{2}$ Sólo salieron 3 números, bajo la redacción de un fraile, y con la misión de combatir en términos satíricos la prensa liberal y reformista de la ciudad. GONZALEZ IMAZ, M. (1910): Los periódicos durante la guerra de la Independencia, 1808-1814. Madrid: Tipografía de la Revista de Archivos, Bibliotecas y Museos, p. 123.
} 
idea del destinatario modela buena parte de los productos comunicativos. Significa que hacer historia de la comunicación pasa, entre otros requisitos, por hacer historia de los públicos receptores.

El público, entendido como sociedad, está históricamente determinado. En el mundo feudal que cuestiona el Cádiz de 1812, la desigualdad jurídica de las personas, junto a un modo de producción de su existencia predominantemente agrario, justifica que, excepto en los grandes núcleos urbanos, no exista necesidad social alguna de una información regular en forma de publicación impresa. El feudalismo carece, en términos generales, de público estable o regular con el tiempo necesario, la motivación, la necesidad y la capacidad adquisitiva e intelectual precisa para comprar y leer, no ya un libro, sino un periódico. Por consiguiente, para que la información escrita, impresa y regular dejase de pertenecer al ámbito reducido de los privilegiados y pasase a ser una actividad pública, había que transformar la sociedad; había que ejecutar la Revolución Burguesa. De ahí que lo que va a suceder en España en 1808, la irrupción de la propaganda dirigida a convencer iguales, se hubiera producido igualmente en la Inglaterra de 1640, en los Estados Unidos de América en 1776 o en la Francia de 1789. De hecho, una de las acusaciones más reiteradas por la contrapropaganda liberal será acusar a ésta de ser un mero plagio de la revolución francesa.

El público que opina y expresa dicha opinión libremente, aparece históricamente con las revoluciones burguesas al establecerse la igualdad jurídica entre las personas, evoluciona en el mismo sentido que el régimen liberal que se implanta y deviene un poderoso instrumento en la medida que se alcance la democracia. En Cádiz, este principio básico del liberalismo burgués lo recoge el artículo 10 del decreto del 10 de noviembre de 1810, al establecer la: "libertad de escribir, imprimir y publicar sus ideas políticas sin necesidad de licencia, revisión o aprobación alguna anteriores a la publicación" y lo ratifica el capítulo II de la Constitución de 1812.

El ciudadano, como partícipe por igual de un sistema político, con derecho a emitir libremente su opinión por el medio que sea y a refrendarla mediante el ejercicio del sufragio, constituye la base sobre la que se asienta la opinión pública moderna. Por eso los diputados liberales de las Cortes de Cádiz atribuyeron a la opinión pública, en primera instancia, la condición de poderoso instrumento de presión. Organizar los grupos de seguidores que actuaban como coro en las tribunas del palacio de San Felipe se convirtió en norma, tanto en el café Apolo como en el Orta, centros neurálgicos de los liberales gaditanos. De hecho, entre los perseguidos de forma inmediata tras la reacción de mayo de 1814, además de diputados y escritores, también se encuentra un sastre, Pablo Rodríguez, "Cojo de Málaga", sentenciado a muerte con los cargos de 
“jefe o capitán, así en Cádiz como en Madrid, de los voceadores de la tribuna pública del Congreso, y el director de las serenatas y otras demostraciones populares" ${ }^{3}$.

Los diputados liberales no se quedaron aquí. También concibieron la naciente opinión pública como la garantía del buen gobierno. Una condición que implicaba una consecuencia lógica: la de educar a los opinadores, o como dice el diputado Flórez Estrada en sus "Reflexiones sobre la libertad de imprenta" (1809), transmitir a esa opinión "las luces" para que obre correctamente. La escuela, pero también la plaza pública, se convertirán en destinatarios de impresos llamados catecismos que, siguiendo el modelo de catecismo religioso, posibilitasen hacer pedagogía de la nueva Constitución. Un paso previo del objetivo superior sintetizado en el artículo 366 de la propia Constitución: "En todos los pueblos de la Monarquía se establecerán escuelas de primeras letras, en las que se enseñará a los niños a leer, escribir y contar, y el catecismo de la religión católica, que comprenderá también una breve exposición de las obligaciones civiles".

Desde este planteamiento podemos explicar por qué toda revolución burguesa constituye una eclosión comunicativa, tanto en Francia, Holanda, España o donde fuere. El planteamiento de la revolución exige prensa, folletos, libros, carteles, etc., en términos impresos y novedosos ${ }^{4}$. Pero también readapta sistema más tradicionales de comunicación como las canciones, los bailes, las representaciones teatrales, los conciertos, las celebraciones y festividades, los juegos, las ropas y, como acabamos de ver, hasta la propia comunicación religiosa readaptando liturgias y catecismo. Sobre todo, construye un nuevo universo repleto de figuras simbólicas que aluden, tanto a los héroes de la revolución como a los principales actos de la misma con banderas, escarapelas, himnos, rotulaciones de calles y plazas, estatuas, cuadros, calendarios, etc. Padilla, gracias al trabajo de Quintana y su Semanario Patriótico, se convierte en el mártir de las nuevas ideas; las plazas de ciudades y pueblos de media España pasarán a llamarse, tras el 19 de marzo de 1812, de la Constitución con placa identificativa; las músicas populares, los himnos más solemnes, la poesías, las obras de teatros y la prosa de los más avezados, se concentrarán en expandir o rebatir las nuevas ideas. La razón de tal eclosión comunicativa no es otra que aglutinar la fuerza social que ejerza de acción motriz en la revolución, dándoles estos elementos de cohesión y ofreciéndoles alternativas con las que se puedan identificar. El objetivo, en buena medida, lo

\footnotetext{
${ }^{3}$ El sastre salvará la cabeza en el último momento gracias a la intermediación del embajador inglés ante el Rey, lo que da una idea de la importancia del personaje. LAFUENTE, M. (1869): Historia General de España. Madrid: Imprenta de Dionisio Chaluie, Parte III, Libro XI, p. 26.

${ }^{4}$ Sólo en el capítulo de folletos conocemos que: "el Avis aux Espagnols de Condorcet (3.000 ejemplares impresos del original francés, además da otros 6.000 sólo de la primera tirada de una de sus versiones en español) o la proclama $A$ la nación española, de Marchena (5.000 ejemplares impresos, además de numerosas copias manuscritas". FUENTES, J.F. y FERNANDEZ SEBASTIÁN, J. (1997): Historia del Periodismo Español. Prensa, política y opinión pública en la España contemporánea. Madrid: Síntesis, p. 31.
} 
podemos identificar de inmediato como la pretensión de canalizar de forma interesada la opinión pública naciente, tal y como sucedió en la misma revolución francesa ${ }^{5}$.

\section{La propaganda a examen: el olvido del público}

Entramos así en el complejo mundo de la propaganda, de esa comunicación polimórfica y de infinitos recursos, tal y como la definiera J. M. Domenach, "canalizada por el poder (político o religioso) para obtener determinados efectos ideológicos o psicológicos" (Ellul, 1969: 8). Sabemos que la palabra propaganda quedó maldita a partir de 1945 por cómo los regímenes totalitarios habían utilizado los medios de comunicación al servicio del poder, y que sus alternativas (desde comunicación persuasiva, estratégica al todo es publicidad) se han reconvertido en instrumentos fundamentales de la acción política actual (Laguna, 2010). Quizá por esta razón, la propaganda ha sido, con ciertas y destacadas excepciones, poco contemplada por la historiografía hasta el momento (Pizarroso, 1990; Almuiña, Egido y Martín de la Guardia, 1992). Es más, desde la historia de la comunicación el principal punto de vista ha sido reconstruir medios y productos, soslayando, cuando no olvidando, a los destinatarios del mensaje propagandístico. En el caso que nos ocupa, el de la Constitución de Cádiz, los esfuerzos básicos han permitido reconstruir buena parte del tejido impresor y periodístico, tanto por la novedad que significa al ser considerada punto de partida del periodismo político ${ }^{6}$, como por la eficacia que se le atribuye.

Sin embargo, si propaganda es sobre todo información intencionada, de acuerdo con la definición de V. Edwards ${ }^{7}$, para entender su funcionamiento y eficacia resultará fundamental conocer al que recibe esa información y sus reacciones. Es como si los historiadores de la propaganda no hubiésemos aprendido nada de los estudios sobre efectos sociales de lo medios que se han venido sucediendo desde principios del siglo XX. Desde el teorema de $\mathrm{H}$. Laswell, formulado con cinco interrogantes para identificar

\footnotetext{
5 Recordemos, en el caso de la Revolución Francesa, cómo el 18 de agosto de 1792 se crea "un verdadero ministerio de propaganda: la sección del Espíritu (con una dotación) de 100.000 libras para la impresión de escritos de propaganda que serían distribuidos en provincias y entre el ejército. ELLUL, J. (1969): Historia de la propaganda. Venezuela: Monte Ávila editores, p. 110

6 “Le cabe a Cádiz el derecho de poderse titular cuna del periodismo político español. Fue entre sus muros donde por primera vez se dio el fenómeno, luego tan extendido, de que las redacciones de los periódicos, que se consideraban representantes de lo opinión pública, intervinieran activamente en la vida política nacional." SOLIS, R. (1978): El Cádiz de las Cortes. Barcelona: Plaza y Janés, p. 437.

7 "Propaganda es la expresión de una opinión o una acción por individuos o grupos, deliberadamente orientada a influir opiniones o acciones de otros individuos o grupos para unos fines predeterminados", citado por PIZARROSO, A.: Historia de la propaganda. Madrid, EUDEMA, 1990, p. 28.
} 
el proceso comunicativo ${ }^{8}$, pasando por la communication research, centrada especialmente en el análisis de los contenidos de los mensajes y el estudio de los efectos (Moragas, 1994; Monzón, 2006), hasta los primeros estudios electorales específicos de Paul F. Lazarsfeld, Bernard Berelson y Hazel Gaudet, sabemos que el primer efecto constatado de toda propaganda es activar predisposiciones existentes entre los receptores (Lazarsfeld, Berelson y Gaudet, 1962). Significa, en pocas palabras, que una buena parte de cómo se va a interpretar la Constitución gaditana tiene mucho que ver con la situación socioeconómica de las personas, con la condición material en que producen su existencia y con la respuesta que ofrece a sus anhelos más inmediatos. Por ejemplo, el caso del militar gallego que irrumpe en el palacio de la Granja en 1836, y ante la pregunta de la reina regente de por qué pide la vuelta del Código gaditano éste le contesta, simplemente, porque la identifica con la abrogación de impuestos ${ }^{9}$. El ejemplo literario tiene su reflejo en la prensa del momento. El Diario de Valencia de 18 de abril de 1820 recogía la siguiente información: "se nos avisa de varias partes que hay colonos, inquilinos y deudores de varias especies, que se creen absueltos de la obligación de pagar sus deudas, a consecuencia de haberse establecido la Constitución".

De igual forma, tampoco hemos incorporado ninguno de los avances efectuados por psicólogos y lingüistas acerca de los mecanismos que forjan marcos mentales que actúan como decodificadores de mensajes por parte de los receptores. Y en un tiempo comunicativo como aquel de 1812, constreñido por frenos estructurales como el analfabetismo o coyunturales como la propia guerra, la conversión de los conceptos legales en símbolos perfectamente identificables (Constitución igual a libertad e igualdad), la traducción de palabras complejas -incluida la de "constitución"- en términos populares -"la Pepa"- o la incorporación de lemas, himnos, banderas, héroes y otros atajos cognitivos, no solo eran básicos para comunicar ideas y objetivos, sino para aglutinar fuerzas y apoyos. El ejemplo más paradigmático lo ofrece el director del

\footnotetext{
${ }^{8}$ Recordemos que Harold D. Laswell fue un especialista en ciencia política que, a finales de los años 40, escribió un artículo que comenzaba con una frase ya legendaria para los estudiosos de la comunicación: "un modo adecuado para describir un acto de comunicación consiste en responder a las preguntas siguientes: ¿quién (comunicador; fuente o emisor) dice qué (mensaje), por qué canal (visual, oral, escrito), a quién (receptor), con qué efectos (cambio de actitudes)", WOLFF, M. (1987): La investigación en la comunicación de masas. Crítica y perspectivas. Barcelona: Paidós, pp. 30 y ss.

${ }^{9}$ Como el soldado, estupefacto y hecho un poste, no contestara, repitió el otro la carga. 'Te pregunto, fíjate bien, que por qué te gusta a ti la Constitución'. El soldado miró al techo, como los chicos que no se saben la lección, y respondió al fin con no poco trabajo: «La quiero, la queremos... porque es mejor'. Ya iba picando en sainete la histórica escena: la inocencia del soldadillo había puesto fin a toda seriedad, y de ello se aprovechó el Alcalde para estrecharle y confundir más a sus compañeros de armas. 'Pero, hombre, explícate mejor: di a Su Majestad en qué te fundas para creer que esa Constitución que ahora defiendes es mejor que otra cualquiera'. Tanto le apremiaron, que el pobre chico se arrancó con sus razones. 'Pues yo no sé... lo que sé es que el año 20, en mi pueblo, que es la Coruña, para servirles, estaba libre la sal (Risas) y libre el tabaco'. PEREZ GALDOS, B. (1976): Episodios Nacionales, "Luchana", Madrid: Alianza Hernando, p. 21-22,
} 
periódico "sulfuroso", creado en Cádiz en 1811, El Robespierre Español, Pedro Pascasio Fernandez Sardino, "erigido en portavoz de la plebe española, quiere escribir en el estilo de ésta, para movilizarla o hacerla reír, según el caso" (Aymes, 2009: 258). Es más, la propia contrarrevolución ideológica, puesta en marcha de forma abrumadora a partir de 1813, además de recurrir a la edición de unos periódicos cuyo público se presuponía ilustrado y, por lo mismo, posicionado, lo que hizo fue, en cuanto los franceses les dejaron, reactivar su red tradicional de comunicación persuasiva directamente conectada con las capas populares, tanto urbanas como campesinas. Clérigos y algún que otro funcionario del patrimonio real, se aprestaron a escribir obras de distinto tamaño y condición que, además de significarlos para la causa e Fernando VII, reiteraban un constante rosario de identificaciones como: liberal o defensor de la Constitución, igual a defensor de Napoleón; Constitución gaditana igual a Constitución francesa de 1791; liberales igual a enemigos de la religión, etc. Es de suponer que con este material argumentativo luego se construyeron los sermones de las parroquias, reiterados en cada acto litúrgico, como el sermón pronunciado en 1810 por Blas de Ostoloza en la Iglesia de los Carmelitas de Cádiz y que luego será editado y difundido en Valencia por "un fiel vasallo y criado del mismo soberano" ${ }^{10}$. Es decir, mensajes básicos y a base de identificaciones simples, repetidos en foros con gran predisposición de los oyentes... No de otra manera cabe entender la construcción del mito del "deseado" que se manifiesta en mayo de 1814.

Por tanto, además de conocer los medios, los mensajes y los fines de la acción propagandística, es básico conocer la credibilidad de la fuente (lo que vamos a llamar directores de la propaganda) y la predisposición de los públicos a asumir e interpretar en clave positiva la comunicación propagandística. Planteado en otros términos y de acuerdo con el tema que nos ocupa, el objetivo sería averiguar cómo en la España de 1808 , en plena contienda armada, con las escasas y anticuadas vías de comunicación interceptadas o anuladas por las tropas francesas y que tanto dificultaron la llegada de los diputados a Cádiz, con una población en su inmensa mayoría analfabeta y con otras rémoras para la comunicación como es el peso del mundo agrario o de la tradición religiosa, ¿cómo es posible que se produzca en un espacio relativamente breve de tiempo una identificación tan importante entre una norma jurídica y una parte de la sociedad española que luchará y morirá por ella a pesar de las reacciones de 1814 y 1823 y a pesar de las desafecciones de antiguos liberales a partir de 1834? Es más, si la Constitución es debatida en un lugar tan alejado como Cádiz, ¿cómo pudo difundirse al resto del país? ¿Por qué una parte importante de los españoles de aquel tiempo se

10 OSTOLAZA, B. (1811): Sermón patriótico-moral, que con motivo de una Misa solemne, mandada celebrar el día 25 de Julio de 1810, en la Iglesia de los RR.PP. Carmelitas de la ciudad de Cádiz por los españoles emigrados de los países ocupados por el enemigo común DIXO el doctor D. Blas de Estolaza, Diputado en cortes, capellán de honor y confesor de S.M.C. el Señor D. Fernando VII, Rey de España y de sus Indias, y del Sr. Infante D. Carlos. Valencia: Imprenta de D. Benito Monfort 
identificaron con un texto de 384 artículos, más una legislación complementaria harto compleja y difícil de entender?

La respuesta tiene que ver con dos planos complementarios de una misma acción comunicativa: con la intensidad y habilidad que los defensores de la Constitución llevaron a cabo su tarea propagandística por todos los medios y soportes posibles; y por otro, con la receptividad y credibilidad que los españoles recibieron estos mensajes. La respuesta, una vez más, evidencia la importancia que para la reconstrucción de los hechos tiene el estudio de la comunicación desde la perspectiva de los receptores.

\section{Directores y receptores de la propaganda}

No hubo una sola guerra entre 1808 y 1814 . Como tampoco hubo un solo perdedor al final. Además de la guerra que se libraba mediante las armas, además de la que se desarrollaba mediante las ideas, estuvo la batalla por convencer a una población de las bondades y beneficios que comportaba la Constitución gaditana. Constitución y libertad de inmediato fueron presentados por los doceañistas como caras de una misma moneda. De la misma manera, la propaganda absolutista combatirá esta identificación con otra no menos contundente, la que igualaba a liberales y afrancesados, haciéndoles "dependientes" del odiado Napoleón, presentado como el anticristo y promotor del fin del mundo ${ }^{11}$. De hecho, entre las obras más señeras de la reacción, la escrita por el obispo de Ceuta, Rafael Vélez (1818: 161-195), un capítulo entero se dedicará a comparar, artículo por artículo, la Constitución española y la francesa de 1791. No será la única ${ }^{12}$.

La propaganda de la libertad, fue, por tanto el principal mensaje que ofrecieron los liberales durante estos años. Eso sí, de forma desigual. En la cronología del periodo revolucionario es fácil detectar tres etapas y un triste epílogo.

Primera etapa (1808-1810): dominada por una exitosa propaganda de guerra, basada en el odio al francés y la sátira a Napoleón, que levantará a una buena parte de la sociedad española. El éxito del mensaje tiene que ver con dos factores claves: en primer lugar, el hecho objetivo de que el ejército francés, no sólo invade, sino que se

\footnotetext{
${ }^{11}$ En 1813 aparecería en Granada el diario El Amigo de los Sabios para, entre otras cosas, desmentir el rumor generalizado en toda la provincia de que el 15 de agosto de 1813 se acabaría el mundo por culpa de Napoleón. Cf. GONZALEZ IMAZ, Op. Cit., p. 50.

${ }^{12}$ CAPMANY, Antonio (1810): Centinela contra franceses. Sevilla, Imprenta Real.
} 
apropia violentamente de los bienes que encuentra a su paso, lo que hace impenetrable cualquier mensaje propagandístico francés o profrancés; en segundo, la credibilidad de la idea de resistencia y levantamiento, puesta en marcha desde el mismo 2 de mayo. De hecho, una causa lleva a la otra: quien pierde cosecha, alimento o bienes mayores por la rapiña del invasor, se convierte en feroz antifrancés por todas las vías, incluidas las de la guerrilla. Y todo ello sin olvidar, tal y como ha destacado Jean René Aymes (2009), el recuerdo muy vivo que todavía existía, sobre todo en la mente de los catalanes, de la Guerra contra la Convención (1793-95).

Los directores de propaganda más destacados de este periodo serán los clérigos en sus diferentes condiciones, que demonizan a los franceses y santifican la rebelión contra ellos. Desde este punto de vista, en esta primera etapa se asienta entre la opinión generalizada de los españoles que el levantamiento antifrancés se hace contra los enemigos de la religión y del verdadero rey. Es el momento, por tanto, en que cuaja la construcción del mito "del deseado", el verdadero rey español, defensor de la religión y de la patria, cautivo por el tirano francés ${ }^{13}$. Es también el momento en que irrumpen los líderes guerrilleros, desde El Empecinado a Espoz y Mina, símbolos del compromiso del pueblo en la lucha en forma de guerrillas contra el francés e idealizados posteriormente. Los Episodios Nacionales de Galdós serían un magnífico ejemplo. Y es también la etapa en que las mujeres salen del papel sumiso en que se las encuadra para convertirse en parte activa y heroica también de la lucha, desde Agustina de Aragón a la condesa de Burata, desde las cigarreras hasta las hermanas de la caridad de Santa Ana (Aymes, 2009: 39). Los públicos alineados a favor de un mismo mensaje se multiplican, justificando la creciente resistencia en el propio devenir de la guerra. Gana "El Deseado", se diluye "El rey de copas, Pepe Botella, el rey intruso".

Segunda etapa (1810-1812): marcada por el debate constituyente y la confrontación propagandística entre liberales y serviles. Aquí, la etiqueta de directores de la propaganda recaería, en primer lugar, en los protagonistas del gran debate que se libra en Cádiz en torno al código constitucional, los 305 diputados cuya cantidad a veces se cuestiona pero que en su mayor parte son hombres de intensa biografía (García León, 2007: 291; Suárez, 2002: 28). Sus intervenciones, impresas de forma resumida en los primeros diarios de sesiones, inspirarán artículos en periódicos, coplas en las calles, representaciones en los teatros y debates en las tertulias. Entre las tertulias gaditanas más destacadas se citan las de doña Margarita López de Morla, que pasó de literaria a política a partir de 1810 y la de Francisca Larrea, esposa del cónsul alemán en Cádiz (Pérez de la Blanca Sales, 2005: 57). Pero es el fenómeno es generalizado. En Valencia, Nicolás María Garelli, además de ser el primer responsable de una cátedra de Derecho

13 "Todos contribuyeron a la creación del mito de un rey en las garras de un tirano", Cf. CALVO MATURANA, A.J. (2005): “Napoladrón Malaparte, el choricero y la madre desnaturalizada. Los papeles antagonistas en el mensaje legitimador de El Deseado", en Ocupació i resistencia a la Guerra del francés, 1808-1814. Barcelona: Museu d'Història de Catalunya, vol I, pp. 627-354. 
constitucional, "dirigía con el pseudónimo de Martelo una tertulia liberal y tuvo un papel decisivo en la discusión suscitada en el claustro a propósito de la felicitación que se envió a las cortes por la supresión del Santo Oficio" (Ardit, 1977: 226). En La Coruña destacaba El Club de la Esperanza, lugar desde donde se editaba, desde 1813, Ciudadano por la Constitución, el periódico más exaltado de la ciudad ${ }^{14}$. La propaganda servil no dudará en vincular este tipo de organizaciones con las aparecidas en Francia de la revolución, las francmasónicas.

Sobre los discursos de los diputados, sus posiciones políticas y sus azarosas vidas existe una abundante bibliografía que apenas nos permite deducir el impacto social que llegaron a tener. Pero de lo que no cabe duda es que el círculo más inmediato, la ciudad de Cádiz, vive con gran intensidad todo lo relacionado con el debate parlamentario. Desde las crónicas del momento, pasando por los reflejos que ofrecen los propios periódicos, hasta las recreaciones literarias coinciden en una ciudad que, más o menos, ofrecía el siguiente cuadro:

"Por la calle Ancha van apareciendo impresos y manuscritos con epígrafes llamativos y caricaturas. En esa calle, que hoy se llama del Duque de Tetuán, se recitan los versos de Arriaza y hallan eco los sarcasmos del diputado Capmany contra el diputado Quintana. Allí pasan, de una a otra mano, los primeros números de aquellos ingenuos periódicos que se llaman El Revisor Político, El Triunfo Americano, El Conciso, La Gaceta de la Regencia, El Robespierre Español, El Amigo de las Leyes, El Censor General, El Diario de la Tarde, El Duende de los Cafés, El Procurador General de la Nación y del Rey. Unos son absolutistas, enemigos de las reformas, y otros defienden las nuevas leyes. Se congregan allí todo el patriotismo y todo el apasionamiento sectario de los tiempos nuevos, la inocencia y el deseo de novedades, la petulancia y el espíritu heroico, el donaire, la fanfarronada y hasta la virtud incorruptible... La calle Ancha, cuando las Cortes de Cádiz empiezan a deliberar, es, a la vez, sala de Conferencias, Bolsa, Ateneo, Círculo, tertulia y Club" (De Tapia, 1961: 26).

Después están los editores y directores de prensa, responsables de la divulgación de las ideas, principios y debates que se concentran en Cádiz. González Imaz nos hace una síntesis de sus protagonistas:

\footnotetext{
${ }^{14}$ Fué su principal redactor D. Marcelino Calero, oficial de la Fábrica de Tabacos, asiduo concurrente y miembro del Club del Café de la Esperanza, centro de los más exaltados liberales; también eran redactores del Ciudadano el Intendente honorario D. Valentín Foronda, Presidente de la Junta Censoria, traductor de las Cartas de Rousseau; D. Manuel Pardo de Xas, ex fraile Agustino, capellán de Ejército retirado, vocal de la Junta Censoria, autor de los folletos Os rogos á un Gallego y El pueblo gallego no quiere la Inquisición, además de varias poesías poco ortodoxas y contrarias á la soberanía del Rey; D. José Oconock, Capitán de fragata, vocal de la Junta Censoria, y D. José Rivera y Gil, teniente Coronel de las Milicias de Túy, abogado del Colegio de la Coruña y autor del folleto El Filósofo Cristiano. Vid. GONZÁLEZ IMAZ, Op. Cit., p. 72
} 
"...sus redactores eran los más expertos, ilustrados y hábiles polemistas, contando con hombres como Gallardo y Mejías que redactaban La Abeja Española; Capmani, El Centinela de la Patria; Ogirando, Sánchez Barbero y Pérez Ramajo, El Conciso, periódico el más batallador, intencionado y agresivo que peleó valientemente más de tres años; Beña, El Correo Político; Gerica y Arriaza, El Diario Mercantil; Clemencín y Tapia, La Gaceta de la Regencia: Alcalá Galiano y Pizarro, El Imparcial; Quintana y Vadillo, El Observador; Daza, Martínez de la Rosa y Gallego, El Redactor General, el más ameno é interesante de todos; Cancelada, El Telégrafo Americano; Calvo de Rozas, Antillón, Fr. Andrés del Corral y Alcalá Galiano, El Tribuno del pueblo Español; Fernández Sardino, El Robespierre Español, en que colaboraba doña Carmen Silva: Alzaibar de la Puente, La Triple Alianza, que desbarró hasta atacar el dogma, con otros muchos periódicos redactados por hombres no vulgares en el manejo de la pluma" (González Imaz, 1910: 27).

Entre los más destacados, el reconocido como patriarca del liberalismo, Manuel José Quintana, promotor del Semanario Patriótico que a los pocos días de su salida, tras el 2 de mayo de 1808, ya contaba con 3.000 suscriptores $^{15}$ y que, según el propio Blanco White reflejaba "los pulsos de la libertad nacional". Quintana viene a ser el arquetipo del periodista del momento: comprometido con la realidad, concibe su función periodística como un medio para expandir sus ideas. El medio es la publicación periódica. El fin, como ocurría antaño con los ilustrados, es extender la luz de la verdad para que actúe de guía al pueblo. En este caso, el fin es dar a conocer la Constitución y sus beneficios. En el ejemplar del Semanario Patriótico del 12 de marzo de 1812 (no 102 y último), Quintana escribe desde la satisfacción de ver concluida la redacción del texto constitucional y siempre en clave de haber conseguido dar al pueblo lo que este necesita... "Vea el pueblo español que pelea no para defender las inmensas propiedades y monstruosos derechos de ciertos cuerpos privilegiados, sino para asegurar su libertad política y civil, y para vivir en adelante con la dignidad correspondiente a un ciudadano español". La convicción es que los males de los españoles se curan con lo legislado en Cádiz. Por tanto, el pueblo ha hecho suya la Constitución... "La abolición de los señoríos, la elección popular de los ayuntamientos, la extinción de las ordenanzas de montes y de caballería, y la igualdad de derechos y obligaciones en todos los españoles, ha hecho en los pueblos una impresión que nosotros mismos no esperábamos".

En esta afirmación del Semanario, acerca del seguimiento que los pueblos pudieran estar haciendo de los debates parlamentarios y de las leyes aprobadas, tiene mucho que ver la reimpresión de los periódicos gaditanos en diferentes ciudades. El

\footnotetext{
${ }^{15}$ Según Blanco White en El Español, no 10, enero de 1811, citado por SEOANE, M.C. (1983): Historia del periodismo en España. Vol 2 "El siglo XIX". Madrid: Alianza Universidad, p. 30
} 
fenómeno tiene una especial incidencia en Valencia, justificado por la acción de una de las familias protagonistas de la revolución: la de los otrora modestos horneros de la plaza de la Pelota, los hermanos Manuel y Vicente Bertrán de Lis ${ }^{16}$. El cronista Vicente Boix nos ha dejado un apretado relato de los sucesos del 23 de mayo de 1808 que nos informa del bautismo revolucionario de los Bertrán (Boix, 1867: 94-96). Su actuación, casi siempre en la sombra, se fundamentaba en un pequeño ejército de labradores y, muy especialmente, en el control de la información. El correo que vía diligencia o postas llegaba desde la capital, la lectura de las publicaciones oficiales -Gaceta- en la plaza de las Pasas, el rumor, la consigna..., fueron las formas en que ejecutaron este control sobre lo que debía o no conocerse. Después vinieron otras, tales como reeditar la prensa de Cádiz en Valencia, crear sociedades patrióticas en las principales capitales, organizar levantamientos, conspirar... Pero siempre el negocio por delante. De hecho, a pesar de la reacción de mayo de 1814, Vicente Bertrán no tendrá excesivos problemas en seguir concurriendo a las subastas públicas, como la celebrada en Madrid, el 24 de enero de 1816, para la contrata de pan; o la de Málaga en diciembre de 1818 para el suministro de víveres a los presidios menores de África ${ }^{17}$, amén de convertirse en el agente español de la banca Rothschild en España ${ }^{18}$. Con las elecciones a diputados, Canga Argüelles y Vicente Bertrán se trasladarán a Cádiz donde tendrán un especial protagonismo en la coordinación del grupo liberal de las Cortes, pero también en la difusión de las medidas que aprueban las Cortes. En efecto, a pesar de la distancia entre Cádiz y Valencia y de la situación de guerra, los hermanos Bertrán de Lis mantendrán una regular correspondencia que no sólo les pone en antecedentes de la marcha de los negocios, sino también de la marcha de sus "otros" asuntos. A fines de 1813, en una de estas cartas de sus agentes, se señalaba en qué consistían estos otros asuntos... "en contestación al dictamen que Vd. me pide, debo decir francamente: que en mi concepto el primer periódico, entre quantos has salido hasta ahora, es el Tribuno del Pueblo Español que se publica en Cádiz dos veces a la semana..."

\footnotetext{
${ }^{16}$ Vicente Bertrán de Lis, antes de amasar su importante fortuna, había sido panadero dos tercios de su vida y apenas sabía leer y escribir. "E1 negocio tenía su sede en Valencia, su ciudad natal, pero poseía amplias ramificaciones, y se convirtió en una red de conspiración liberal al terminar la guerra en 1814". JANKE, P. (1974): Mendizábal y la instauración de la monarquía constitucional en España (1790-1853). Madrid : Siglo XXI editores, p. 9. Más rasgos biográficos de la familia Bertrán de Lis y su potencial económico en ARDIT LUCAS, M. (1977): Revolución liberal y revuelta campesina. Barcelona: Ariel, pp. 120 y ss.

${ }^{17}$ Vid. Decretos del Rey D. Fernando VII. Tomo III (1817) Madrid: Imprenta Real, p. 453; Diario de Madrid, 30 de enero de 1818.

18 "En la ciudad de Cádiz cercada por los franceses, Bertrán de Lis debió hacer buenos negocios de abastecimiento, que posiblemente llegaron a oídos de Nathan Rothschild y le animaron a entrar en contacto con él. Por otra parte, el comerciante y financiero valenciano contaba ya por aquellos años con un joven empleado que pronto descollaría en el panorama político-económico español: el gaditano Juan Álvarez Mendizábal, con el que debió organizar buena parte del aprovisionamiento de la ciudad durante el pleno de las Cortes". LOPEZ-MORELL, M.A. (2005): La casa Rothschild en España (1812-1941). Madrid: Marcial Pons, p. 33. Cf.
} 
La iniciativa de reimprimir en Valencia la prensa gaditana no es nueva. En 1811 se ha hecho con El Robespierre Español, del que sólo tenemos constancia que saliera un número. Después, en el mismo año, El Conciso, si bien en Valencia hubo que disimular su título por el menos sospechoso de El Logógrafo o el Monitor Secreto. Pero cuando Manuel Bertrán decide públicamente comprometer su nombre con la reedición del Tribuno gaditano, es ya 1813 , es tiempo de intentar consolidar la Constitución difundiéndola, propagándola. Así lo declara el prospecto de presentación: "La Constitución nos llama desde luego a todos para formar parte integrante de la soberanía en las elecciones, y removiendo trabas afrentosas, abre al simple ciudadano el camino para llegar a las primeras dignidades del reyno. Y ¿a quién le estará demás adquirir una tintura de las materias sobre que habrá de fallar soberanamente algún día? Y pues el Tribuno abraza lo mas selecto de todas, debo decir a vd., que hará a mi entender un servicio importantísimo a esta provincia, generalizando dicho periódico".

Tercera etapa (1812-1814): marcada por la necesidad de difundir el texto constitucional a toda la población, a medida que la guerra lo permitía, y así combatir la propaganda servil, cada vez más intensa. Acabamos de ver, para el caso de Valencia, cómo una de las estrategias será la reimpresión de la prensa gaditana. El fenómeno se generaliza en estos momentos y no tanto por la propia reedición, sino porque libres progresivamente los caminos de la trabas de la guerra, el correo de ejemplares se multiplica. La expectación justifica la atención a las lecturas públicas que se generalizan. Así lo constata quien pretende criticar el exceso de propaganda: "Los instruidos no se saciaban de leer nuestros diarios de cortes, redactores, concisos, diarios mercantiles, constitución, papeles de Cádiz. La novedad, el estilo, las materias que se trataban, el entusiasmo con que se leian; los aplausos que algunos les daban iban insensiblemente formando un gusto nuevo, y como variando la opinión pública en materias de gobierno y de estado. En las plazas, alamedas, cafés, casas de grandes, hasta en el albergue de los infelices, en todas partes se leían los papeles públicos, y todos los escuchaban como si fueran los anuncios de mayor felicidad, como unos oráculos" (Vélez, 1818: 235).

Este fomento de la comunicación oral, en aquellos territorios donde los coloquios forman parte de su literatura tradicional, alumbrará periódicos singulares. Es el caso del valenciano Saro Perrengue y el Dotor Cudol, una publicación aparecida en 1813 por iniciativa de Manuel Civera, cuya periodicidad se marcaba por "conversaciones". Se trata, en síntesis, del ejemplo más nítido que tenemos de la forma en que un carretero de la huerta próxima a la ciudad de Valencia, Godella, era ilustrado en los contenidos de la Constitución en su misma lengua, en valenciano, por un abogado de Valencia, "EI so Dotor Cudol".

Las necesidades propagandísticas resultaban mayúsculas, no sólo por la oposición servil, sino porque el destinatario principal, el pueblo, apenas tiene más referente de 
lo que puede significar la Constitución que el recuerdo de lo ocurrido en Francia. Y esa identificación, como ya hemos advertido, se la habían apropiado los absolutistas como argumento central de su discurso antiliberal. Era preciso establecer una especie de tabla de equivalencias que diese sentido popular a cada uno de los artículos y valores recogidos en su articulado. Para empezar, organizando una gran celebración "nacional" con motivo de la aprobación del Código el 19 de marzo, una gran "fiesta constitucional" tal y como la ha denominado el profesor Chust Calero (1995: 243-45). Una celebración que identificara Constitución con liberación, tanto del invasor como del señor feudal, y que contagiara entusiasmo y adhesión..." El 19 de marzo era el señalado: en él iba á sentirse el benigno influjo de la reforma en la mayor plenitud. Los periódicos lo prometían, los panegiristas se multiplicaban. Las plazas, las calles, las fondas, los cafés, todos publicaban que esta reforma general era la constitución. Los templos, los teatros, los juegos de villar repetían el eco constitución. Cádiz, la Isla, la marina, el ejército, el comercio, el artesano el sabio, el ignorante, todos hablaban constitución...la ilusión era general, universal el entusiasmo" (Vélez, 1818: 117-118). En términos generales, la fiesta debió de resultar un éxito, sobre todo en la misma Cádiz donde, según El Conciso de 20 de marzo, a pesar de la climatología adversa, una gran multitud se manifestaba por sus calles al grito de "iViva la Constitución, vivan las Cortes, viva la nación!".

Sin duda, una de esas tablas de equivalencia que pretendieron traducir a términos perfectamente comprensibles conceptos tan extraños hasta entonces como la propia palabra "constitución", fueron los catecismos políticos como el de Fermín Castañón, titulado: Catecismo político arreglado a la Constitución de la Monarquía Española para ilustración del pueblo, instrucción de la juventud y uso de las escuelas de primeras letras $^{19}$. Se trata, como se desprende por el propio titulo, de una iniciativa a mitad de camino entre el sistema tradicional de enseñaza de la religión y la práctica efectuada en tiempos de la revolución francesa para implicar a los campesinos en la redacción de los "cahiers de doleants" (Capitán, 1978: 57-58). La represión de 1814 provocará la desaparición de muchos de estos catecismos, pero todavía pueden leerse los editados en Madrid, distribuido por la librería de Arribas, Barcelona, por la librería de la plaza de San Jaime, o los de Jaén, Córdoba y Málaga. Además, esta estrategia divulgativa en forma de pequeños catecismos tendrá amplio seguimiento en los procesos de independencia americanos.

Propagar la Constitución mediante el siempre fructífero sistema de establecer un sistema de identidades, podía tener ciertos resultados. Así, frente al pasado feudal, los valores de la igualdad y de la libertad podían calar sin excesivos problemas entre las personas. De hecho, en las siguientes batallas de 1820 y 1836 tuvieron un

\footnotetext{
19 Existe una edición facsimilar, realizada por Ediciones Tres Fronteras (Murcia, 2008) con estudio preliminar a cargo de Enrique Ujaldón.
} 
protagonismo indudable. Sin embargo, la prueba de fuego para la credibilidad del nuevo orden legal iba a ser la forma y modo en que se implantara allí donde los franceses ya no estaban. Inicialmente, el procedimiento oficial adoptado para hacer público el nuevo marco legal consistirá en la lectura de la Constitución, en plaza pública, por un escribano. A continuación, en la misma medida que se retiraban los franceses de los pueblos y entraban las nuevas autoridades, la obligación eran jurar públicamente la Constitución, lo que provocó serios conflictos con más de una autoridad eclesiástica. También se enviaron comisionados a distintas ciudades con el encargo de promover el conocimiento y la adhesión, hasta el extremo que el citado padre Vélez llegaría a afirmar que: "No hubo provincia o ciudad principal á la que no se destinaron algunos con el fin de establecer la constitución, sembrar las máximas de las reformas, sostenerlas con el mayor tesón" (Vélez, 1818: 238). Sin embargo, la conjura de los afectados por el cambio jurídico, desde el rey hasta el último empleado de la administración feudal, sin olvidar el peso capital de la Iglesia y del ejército, abortó la generalización social de la Constitución.

Epilogo (1814): donde se dan la mano la contrapropaganda y la reacción. Desde el inicio mismo de la convocatoria del proceso constituyente, frente al estamental tradicional, la propaganda antiliberal había aflorado. Al frente de la misma se situarán exponentes de una iglesia o de una antigua administración feudal que han quedado desarbolados por la invasión y condenados por la revolución. Es el caso de los eclesiásticos Alvarado, de la Orden de Predicadores, que bajo el pseudónimo de El Filósofo Rancio combatía las reformas y a liberales como Bartolomé José Gallardo, bibliotecario del Congreso de diputados y notorio escritor anticlerical en diarios como La Abeja Española; del fraile Agustín de Castro, responsable de La Atalaya de la Mancha, uno de los principales diarios absolutistas que empezó publicándose en Palma de Mallorca en 1814 para editarse luego en Madrid; o del fraile capuchino que venimos citando, Rafael de Vélez, que colaboraba en varios periódicos. Todos ellos escribían animados por su fe y con un sentimiento de cruzada que les impulsaba a intensificar sus acciones propagandísticas. El caso del carmelita descalzo, Manuel Traggia, hermano del general Marqués del Palacio, es un buen ejemplo. Después de publicar en Valencia el periódico El Amigo de la Verdad, realizará en Sevilla otro bajo el titulo de El Vencedor Católico y finalmente, en Mallorca, acabará publicando El Amante de la Religión y El Antitomista en las Cortes ${ }^{20}$.

Además de Mallorca, la reacción tuvo su otro epicentro en Valencia. Allí aparecerán, en abril de 1814, los últimos periódicos que, más que propagar ideas absolutistas,

20 "El Anti-Tomista es una impugnación en forma de diálogo al opúsculo que con el título de Las Angélicas Fuentes ó El Tomista en las Cortes había publicado el Presbítero y diputado por Játiva D. Joaquín Lorenzo Villanueva, tratando de probar nada menos que las Cortes eran Tomistas y seguían en sus decisiones

la doctrina del Angélico Doctor Santo Tomás de Aquino". GONZÁLEZ IMAZ, op. Cit., p.52 
apostaban directamente por la reacción antiliberal. Unos diarios que, una vez más, se reimprimirán en Mallorca y Sevilla. En primer lugar, Lucindo, creado en abril de 1814 por un empleado en rentas decimales, Justo Pastor Pérez, que ya se había destacado por su colaboración en El Procurador de la Nación y del Rey. Los contenidos de Lucindo no dejan lugar a la duda. Un análisis del número 6, aparecido en los inicios del mes de mayo, trasluce de forma nítida la reacción que ya se preparaba. En primer lugar, la identificación que realiza de los liberales como servidores de Napoleón... "Napoleón, padre y gefe de tanto malvado y parricida como para mengua nuestra ha levantado su cabeza entre nosotros (...) enemigos domésticos, á traidores, que intentan y procuran por todos los medios imaginables asesinar á V.M. destruir su trono, acabar con la religión sacrosanta (...) iQuántas veces he anunciado á la nación que los llamados liberales eran tan franceses como Napoleón! ¡Cuantas que eran enemigos de V.M.!".

Contra el monarca, contra la religión y a favor de Napoleón, son los tres calificativos atribuidos al liberalismo que esgrime el propagandista "servil". Pero apuntamos que la conspiración ya se adivina en función de la osadía con que el periódico habla contra la Constitución... "Deshaceos de ellos, Señor, si deseáis hacernos felices: reprimid á estos hombres desbocados y para vengar el escándalo que ha causado el Liberal (periódico de Cádiz), quemad, Señor, hasta la fundición y prensas que han servido para tan infernal escrito. Pero no os contentéis con esto para castigar tan execrable crimen. Solo este escrito, aun cuando V.M. no tuviese otros motivos, que sí los tiene; le autoriza para quemar por mano del verdugo la maldita Constitución".

La organización del levantamiento militar antiliberal se efectuó en Valencia. Y más concretamente, la conspiración se realizó bajo la tapadera de una publicación periódica titulada El Fernandino. El periódico lo redactaba el canónigo Blas Ostalaza ${ }^{21}$, antiguo inquisidor general, confesor del hermano del Rey y diputado por el Perú en unas Cortes que siempre anatemizó. Lo había empezado a publicar con motivo de la vuelta de Fernando VII e inmediatamente consiguió que se reimprimiese en Mallorca y, a partir de julio de 1814, en Madrid. Su misión era parecida a la desempeñada por la publicación anterior, si bien desde este periódico fue donde se redactó el conocido "Manifiesto de los Persas".

Es obvio que el éxito de la propaganda se mide por los resultados. En ese sentido, si tenemos en cuenta las muestras de júbilo que acompañaron a Fernando VII en su regreso, las procesiones multitudinarias que se organizaron para recibirlo, o los actos contra la Constitución que se sucedieron en numerosas plazas rompiendo la placa

\footnotetext{
${ }^{21}$ El Defensor de los afligidos y Desesperados, de 7-X-1820, recogió una extensa "Apología del señor don Blas Ostolaza" que en clave de humor reconstruía parte de su vida. Firmado por José María Valdés, ha sido recogido por GIL NOVALES, A. (1979): Textos exaltados del Trienio Liberal. Madrid: Ediciones Júcar, pp. 67-90.
} 
rotuladora, concluiremos que la propaganda servil fue más eficaz que la liberal. Sin embargo, el cambio no se produjo sólo por la fuerza de la opinión, sino por la acción de las armas de un ejército encabezado por el Capitán General de Valencia. Es más, los sucesivos intentos de restaurar la Constitución hasta 1836, tanto los fallidos como los exitosos, se verán sofocados por la reacción militar. El absolutismo, coherente con el feudalismo que defiende, confiaba más en la fuerza para mantenerse que en las ideas. Por eso restauró el Santo Oficio a partir de 1814, con el fin expreso de eliminar tanto a los liberales como a sus publicaciones. Y por eso provocó la práctica desaparición de periódicos en lo seis años que duró la primera parte del reinado absoluto de Fernando VII, "el deseado". Con todo, a pesar de las detenciones y ejecuciones, a pesar de la represión de y la Inquisición, la propaganda de la libertad solo tardó en rebrotar seis años.

\section{Bibliografía}

ARDIT LUCAS, M. (1977): Revolución liberal y revuelta campesina. Barcelona: Ariel.

Aymes, J-R.(2009): La Guerra de la Independencia, (1808-1814): calas y ensayos. Madrid: CSIC y Ediciones Doce Calles, S.L.

ALMUIÑA, C. EGIDO, T. Y MARTín DE LA GUARDIA, R. (1992): “La crisis del Antiguo Régimen en España. La propaganda como arma de combate", en XVII Congreso Internacional de Ciencias Históricas, Madrid: UCM.

BOIX, V. (1867): Crónica de la provincia de Valencia. Madrid: Imprenta de Rubio y cia.

CAPITÁN DÍAZ, A. (1978): Los catecismos políticos en España (1808-1822). Un intento de educación política del pueblo. Granada: Caja General de Ahorrros.

CHUST CALERO, M. (1995): “La Fiesta Constitucional. Cádiz, 1812”, en VI Encuentro: De la Ilustración al Romanticismo. Juego, fiesta y trasgresión, 1750-1850. Cádiz: Servicio Publicaciones Universidad de Cádiz.

DE TAPIA, E. (1961): Luz y taquígrafos. Un siglo de Parlamento en España. Madrid: Aguilar

ELLUL, J. (1969): Historia de la propaganda. Venezuela: Monte Ávila editores

GARCIA LEON, J.N. (2007): En torno a las Cortes de Cádiz. Cádiz: Quorum Editores.

GONZÁLEZ IMAZ, M. (1910): Los periódicos durante la guerra de la Independencia, 1808-1814. Madrid: Tipografía de la Revista de Archivos, Bibliotecas y Museos. 
LAGUNA PLATERO, A. (2010): Las claves del éxito político: por que votan los ciudadanos. Madrid: Península.

LAZARSFELD, P., B. BERELSON Y H. GAUDET (1962): El pueblo elige. El proceso de formación del voto durante una campaña presidencial. Buenos Aires: Ed. Imprenta López, p. 88. Título original: The peoples choice. How the Voter Makes up his Mind in a Presidential Campaign, (la ed. 1944). New York: Columbia University Press.

MONZÓN, C. (2006): Opinión pública y comunicación política. Madrid: Técnos, p. 228

MORAGAS, M. (1984): Teorías de la comunicación. Investigaciones sobre medios en América y Europa. Barcelona: Gustavo Gili, p. 43.

PÉREZ DE LA BLANCA SALES, P. (2005): Martínez de la Rosa y sus tiempos. Barcelona: Ariel.

PIZARROSO, A. (1990): Historia de la propaganda. Madrid: EUDEMA.

SUÁREZ, F. (2002): Las Cortes de Cádiz, Madrid: Rialp

VÉLEZ, R. (1818): Apología del altar y del trono. Tomo II. “Apología del trono". Madrid: Imprenta de Cano. 